This item was submitted to Loughborough's Research Repository by the author.

Items in Figshare are protected by copyright, with all rights reserved, unless otherwise indicated.

\title{
Microgeometrical tooth profile modification influencing efficiency of planetary hub gears
}

PLEASE CITE THE PUBLISHED VERSION

https://doi.org/10.1504/IJPT.2018.10011451

\section{PUBLISHER}

(c) Inderscience Enterprises Ltd.

\section{VERSION}

AM (Accepted Manuscript)

\section{PUBLISHER STATEMENT}

This work is made available according to the conditions of the Creative Commons Attribution-NonCommercialNoDerivatives 4.0 International (CC BY-NC-ND 4.0) licence. Full details of this licence are available at: https://creativecommons.org/licenses/by-nc-nd/4.0/

\section{LICENCE}

CC BY-NC-ND 4.0

\section{REPOSITORY RECORD}

Fatourehchi, Ehsan, Mahdi Mohammadpour, P.D. King, Homer Rahnejat, G. Trimmer, B. Womersley, and A. Williams. 2019. "Microgeometrical Tooth Profile Modification Influencing Efficiency of Planetary Hub Gears". figshare. https://hdl.handle.net/2134/26007. 


\title{
Microgeometrical Tooth Profile Modification Influencing Efficiency of Planetary Hub Gears
}

\author{
Fatourehchi, $\mathrm{E}^{1}$, Mohammadpour, $\mathrm{M}^{{ }^{*}}$, King, P.D. ${ }^{1}$, Rahnejat, $\mathrm{H}^{1}$, Trimmer, $\mathrm{G}^{2}$, Womersley, $\mathrm{R}^{2}$ and \\ Williams, $\mathrm{A}^{2}$ \\ ${ }^{1}$ Wolfson School of Mechanical Engineering, Loughborough University, LE113TU \\ ${ }^{2}$ JCB Transmission, Wrexham Industrial Estate, Wrexham, UK \\ ․m.mohammad-pour@lboro.ac.uk
}

\begin{abstract}
:
Planetary hub systems offer desired speed and torque variation with a lighter, compact and coaxial construction than the traditional gear trains. Generated friction between the mating teeth flanks of vehicular planetary hubs under varying load-speed conditions is one of the main sources of power loss. Modification of gear tooth geometry as well as controlling the contacting surface topography is the remedial action.
\end{abstract}

The paper studies the effect of tooth crowning and tip relief upon system efficiency. It includes an analytical elastohydrodynamic analysis of elliptical point contact of crowned spur gear teeth. The analysis also includes the effect of direct contact of asperities on the opposing meshing surfaces. Tooth contact analysis (TCA) is used to obtain the contact footprint shape as well as contact kinematics and load distribution. A parametric study is carried out to observe the effect of gear teeth crowning and tip relief with different levels of surface finish upon the planetary hubs' power loss.

Keywords - Transmission efficiency, Gear tooth modification, Planetary wheel hub system, Surface finish

\section{1-Introduction}

A wide range of mechanical applications, from gas turbines to automotive powertrains, use planetary gears. This is because they provide a large set of variable transmission ratios and improved efficiency relative to fixed axes transmissions [1].

One of the main concerns in any gearing application is frictional power losses. The other is noise and vibration, mainly due to low damping characteristics of lubricant film under the prevalent elastohydrodynamic conditions in teeth pair contacts subjected to medium to high loads. This was 
first demonstrated by Dareing and Johnson [2], experimenting with a pair of representative wavy surfaced discs. Numerical analysis carried out under the same conditions by Mehdigoli et al [3] agreed with the findings of Dareing and Johnson [2] and showed the lightly damped nature of elastohydrodynamic contacts. The study in [3] showed that a tribodynamic model is required to simultaneously study vibration and efficiency of gearing systems. A large number of numerical and experimental studies have been devoted to power losses of transmission systems of different configurations under transient dynamic conditions. These include the work of $\mathrm{Li}$ and Kahraman [4] for the case of spur gear pairs and that of De la Cruz et al [5] for the case of helical gears of vehicular transmission systems. In the case of the former, a model based on mixedelastohydrodynamic (EHL) regime of lubrication was used. In the case of the latter a transient elastohydrodynamic analysis was carried out.

Mohammadpour et al. [6] developed an integrated multi-body dynamics and lubricated contact mechanics model to predict the transient behaviour of efficiency as well as noise, vibration and harshness $(\mathrm{NVH})$ of hypoid gear pairs of vehicular differentials. They showed that refining $\mathrm{NVH}$ and transmission efficiency can lead to contrary requirements. The non-Newtonian elastohydrdynamics is the dominant regime of lubrication in such contacts [7]. Therefore, the tribological contacts should be represented by lubricant shear characteristics obtained through combined analytical and experimental studies by Evans and Johnson [8]. The resulting analytical approach would reduce the computational burden of a numerical analysis of the meshing gear teeth pairs. In such an approach, the lubricant film thickness is estimated using extrapolated lubricant film thickness formulae, such as that presented by Chittenden et al [9]. This approach approximates the transient contact dynamics with instantaneous quasi-steady solution of the lubricated contact problem. This approach is computationally quite efficient [10] and as De la Cruz et al [5] show conforms well with full numerical solutions. The same approach is reported by Fatourehchi et al. [11], estimating gear contact power losses of high performance transmission systems, using different gear teeth modifications and their effects upon gear power loss and system durability.

With regard to planetary gears, Talbot et al. [1] carried out experimental work on planetary gears' power losses under various operating speeds and applied torques, inlet oil temperature, numbers of planets and surface roughness of meshing teeth pairs. They showed that a reduction in the oil 
sump temperature and an improved in surface topography would decrease the planetary gear systems power loss. This is an expected outcome as sources of contact friction are due to viscous shear of the lubricant and direct contact of real rough surfaces. Marques et al. [12] performed experimental investigation of a wind turbine planetary gear system, measuring the system power loss with different gear oils and operating conditions. They compared their measured results with a numerical model. Inalpolat and Kahraman [13] presented a dynamic model for planetary gears of automotive transmissions, but used a dry contact model taking into account elastic deformation of mating teeth in their rigid body dynamics approach. Therefore, their model is suited for a dynamics' study, but not for accurate prediction of friction in lubricated contacts. Recently, Mohammadpour et al [14] presented a tribodynamic model of planetary gears for hybrid powertrain systems, studying the effect of power source mode upon transmission efficiency and NVH performance.

Planetary hub systems of trucks and off-highway vehicles are subject to high loads at low operating speeds. These promote the worst tribological conditions, resulting in contact pressures of the order of 1.2 GPa and a sub-micrometre lubricant film thickness. Planetary hub systems are also particularly compact, yielding highly concentrated tooth meshing contacts. Therefore, a methodical approach capable of predicting the parameters which affect planetary hub gears' efficiency is the key to achieving efficient systems.

The current study presents a parametric analysis of the effect of different extents of tooth longitudinal crowning on the planetary hub gears' power loss. It also takes into account the influence of roughness of meshing surfaces upon system efficiency.

\section{2- Planetary hub configuration}

Figure 1 is schematic representation of planetary hub gear. It shows the power flow from the differential gearbox through to the wheel hub. It also shows the transmission ratio, torques and speeds at the different stages of the axle system. Power is transmitted through the sun gear, attached to the input shaft. The ring gear is fixed to the transmission housing. The output power is transmitted to the wheels through the carrier. The planetary system comprises three planet gears. It is assumed that there is no misalignment in the planetary system, and the input power from the sun gear is equally divided among the planets. 


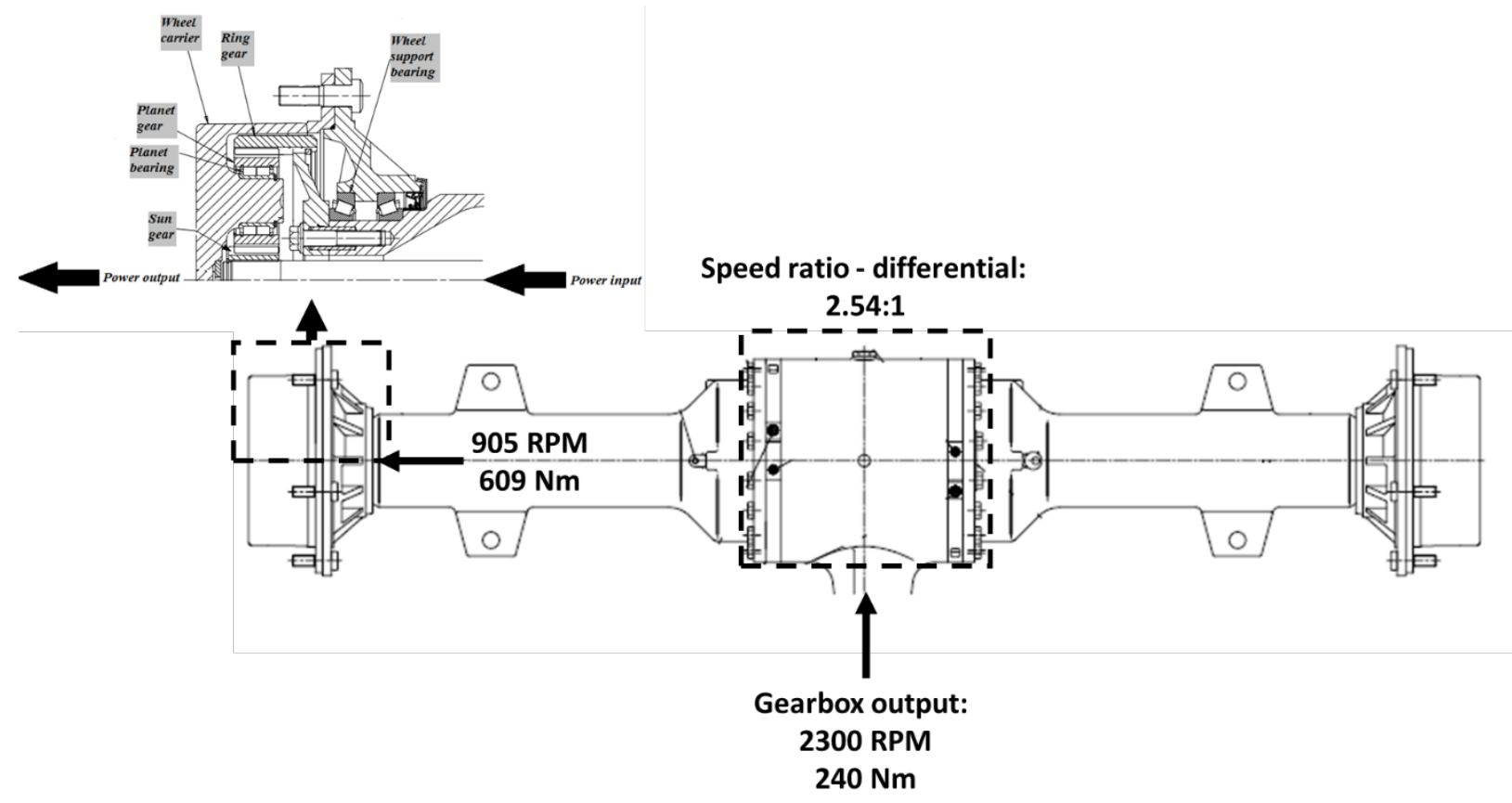

Figure 1: Schematic representation of the planetary wheel hub gears

\section{3- Method of Analysis}

The method integrates Tooth Contact Analysis (TCA) and an analytical elastohydrodynamic gear teeth pair contact model. TCA is developed to obtain the instantaneous radii of curvature of teeth at any instant of rolling and sliding contact as well as contact surface velocities and the orthogonal meshing contact loads for a complete meshing cycle. These parameters form the input to the elastohydrodynamic analysis, yielding viscous and boundary friction contributions for the planetary hub system power loss.

\section{1 - TCA}

The TCA model is based on the approach of Vijayakar [15], and $\mathrm{Xu}$ and Kahraman [16]. The developed model is used to obtain the instantaneous contact geometry, rolling and sliding velocities and load share per teeth pair contact $[16,17]$ for simultaneous meshing of sun-planet and planet-ring contacts in the planetary hub system.

\section{2 - The elastohydrodynamic contact model}


High contact pressures, up to $1.2 \mathrm{GPa}$, of the planetary wheel hub system of trucks and offhighway applications can result in asperity interactions on the mating teeth pairs. Therefore, mixed regime of lubrication is expected. Friction in the mixed regime of lubrication comprises two contributions; viscous shear of a thin lubricant film and direct interaction of asperities on the opposing boundary solid surfaces. Therefore, the instantaneous power loss is obtained as:

$P_{l o s s}=\left(f_{v}+f_{b}\right) U_{s}$

\subsection{1 - Boundary friction}

The thin lubricant films in the elastohydrodynamic contact of gear teeth pairs are usually of the order of surface roughness of the contacting surfaces, particularly due to the high generated heat and the usually starved inlet boundary conditions in practice [18].

Greenwood and Tripp [19] presented a method for the prediction of boundary friction, assuming a Gaussian distribution of asperity peaks. This is a function of the Stribeck's oil film parameter: $1<\lambda=\frac{h_{c 0}}{\sigma}<2.5$ which specifies the fraction of the load carried by the asperities in the contact footprint. Thus [19]:

$W_{a}=\frac{16 \sqrt{2}}{15} \pi(\xi \beta \sigma)^{2} \sqrt{\frac{\sigma}{\beta}} E^{\prime} A F_{5 / 2}(\lambda)$

where, the statistical function $F_{5 / 2}(\lambda)$ for a Gaussian distribution of asperities is obtained as [10, 20]:

$F_{5 / 2}= \begin{cases}-0.004 \lambda^{5}+0.057 \lambda^{4}-0.29 \lambda^{3}+0.784 \lambda^{2}-0.784 \lambda+0.617 & \text { for } \lambda<2.5 \\ 0 ; & \text { for } \lambda \geq 2.5\end{cases}$

For steel surfaces, the roughness parameter $(\xi \beta \sigma)$ is generally in the range $0.03-0.07 . \sigma / \beta$ which is defined as average asperity slope [10], is in the range of $10^{-4}-10^{-2}$. For the current study: $\xi \beta \sigma=$ 0.055 and $\sigma / \beta=10^{-3}$. These were measured through Focus-Variation technology, using Alicona with a vertical measurement sensitivity of $1 \mathrm{~nm}$ and lateral measurement sensitivity of $0.174 \mu \mathrm{m}$. It should be noted that Greenwood and Tripp model [19] also uses an average asperity height radius, $\beta$. The method is therefore applicable for run-in gear teeth pair contacts, with fairly smoothened surfaces. Better representation can be obtained through measurement and generation of surface-specific distribution as highlighted by Leighton et al [21]. 
Friction generated by asperities interaction should be taken into account in mixed and boundary regimes of lubrication. A thin adsorbed film resides at the summit of the asperities or entrapped in their inter-spatial valleys. This film is subjected to non-Newtonian shear; thus, boundary friction $f_{b}$ becomes [18]:

$f_{b}=\tau_{L} A_{a}$

where, $\tau_{\mathrm{L}}$ is the lubricant's limiting shear stress [18]:

$\tau_{L}=\tau_{0}+\varepsilon P_{m}$

where, the mean (Pascal) pressure $P_{m}$ is:

$P_{m}=\frac{W_{a}}{A_{a}}$

The asperity contact area is expressed as [19]:

$A_{a}=\pi^{2}(\xi \beta \sigma)^{2} A F_{2}(\lambda)$

The statistical function $F_{2}(\lambda)$ is calculated as $[10,20]$ :

$F_{2}(\lambda)= \begin{cases}-0.002 \lambda^{5}+0.028 \lambda^{4}-0.173 \lambda^{3}+0.526 \lambda^{2}-0.804 \lambda+0.500 & \text { for } \lambda<2.5 \\ 0 ; & \text { for } \lambda \geq 2.5\end{cases}$

\subsection{2 - Viscous friction}

Evans and Johnson [8] provided an analytical method to obtain viscous friction in elastohydrodynamic contacts, where the coefficient of friction is obtained as:

$\mu=0.87 \alpha \tau_{0}+1.74 \frac{\tau_{0}}{\bar{p}} \ln \left[\frac{1.2}{\tau_{0} h_{c 0}}\left(\frac{2 K \eta_{0}}{1+9.6 \xi}\right)^{\frac{1}{2}}\right]$

where, $\xi$ is:

$\xi=\frac{4}{\pi} \frac{K}{h_{c 0} / R}\left(\frac{\bar{p}}{E^{\prime} R K^{\prime} \rho^{\prime} c^{\prime} U_{r}}\right)^{1 / 2}$

The lubricant film thickness under the instantaneous operating conditions is obtained using the regressed extrapolated lubricant film thickness formula of Chittenden et al. [9]: 
$h_{c 0}^{*}=4.31 U_{e}^{0.68} G_{e}^{0.49} W_{e}^{-0.073}\left\{1-\exp \left[-1.23\left(\frac{R_{y}}{R_{x}}\right)^{2 / 3}\right]\right\}$

where, the dimensionless groups are expressed as:

$U_{e}=\frac{\pi \eta_{0} U}{4 E_{r} R_{x}}, W_{e}=\frac{\pi W}{2 E_{r} R_{x}^{2}}, G_{e}=\frac{2}{\pi}\left(E_{r} \alpha\right), h_{c 0}^{*}=\frac{h_{0}}{R_{x}}$

Therefore, the generated viscous friction, using equation (9) becomes:

$f_{v}=\mu W$

\section{4- Results and discussion}

The planetary wheel hub gears of the JCB Max-Trac rear differential is studied here. The input torque to the sun gear from the differential is $609 \mathrm{Nm}$ at the speed of $906 \mathrm{rpm}$.

Firstly, the effect of gear teeth longitudinal crowning is considered. Secondly, the influence of gear teeth tip relief modification is considered. Two parameters are involved in the tip relief modification: the extent of tip relief and the length of the relieved region. The results are presented for the cyclic meshing power loss of both the axle's planetary wheel hub sets.

Figure 2 is a schematic representation of teeth crowning and tip relief modification. In order to study the effect of surface roughness on the gear pair power loss, the tooth Root Mean Square (RMS) surface roughness for different crowning and tip relief modification are varied in the range 0.4-3.6 $\mu \mathrm{m}$. The surface roughness of the current design of planetary hub gears of the JCB Max-Trac rear differential is $1.6 \mu \mathrm{m}$. 


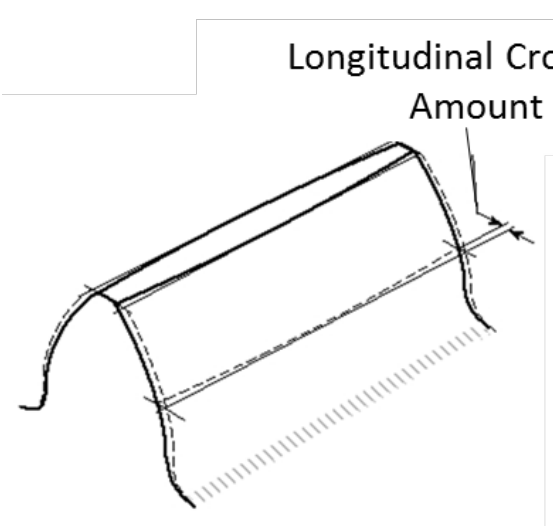

(a)

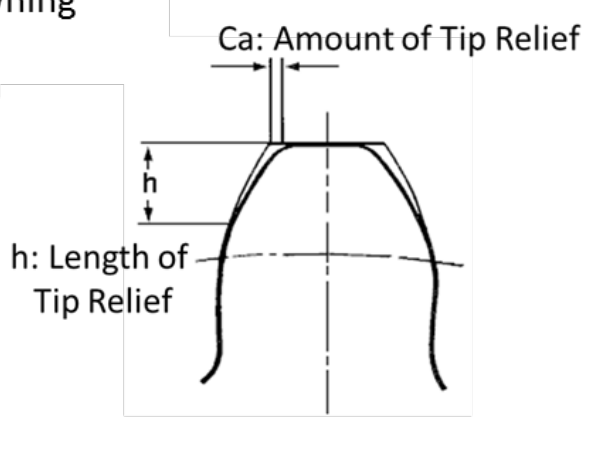

(b)

Figure 2: Schematic representation of gear teeth modification; (a) crowning (b) tip relief

\section{1- Effect of tooth profile crowning}

Idealised spur gears with finite line contact geometry are very sensitive to misalignment and manufacturing errors which cause edge-loading of their contacts, leading to edge stress generated pressure spikes, similar to that of straight-edged rolling element bearings [22, 23]. One repercussion of this is localised wear or fatigue spalling (pitting) due to inelastic sub-surface stresses [24]. Another is increased gear noise. Like rolling element bearings, where their sharp edges are crowned or relieved through a dub-off radius to reduce the edge stress discontinuity [25], the simplest way to avoid edge loading is through crowning of gear teeth surfaces. Several investigators have studied improvements in the meshing contact stress distribution for misaligned spur gears through crowning [26, 27].

In order to study the effect of crowning on power loss, the amount of crowning is varied between $50 \%-150 \%$ of the current in-field design. The amounts of applied crowning used in the current study are listed in Table 1. 
Table 1: Amount of applied crowning for different scenarios

\begin{tabular}{|c|c|c|c|}
\hline & \multicolumn{3}{|c|}{ Crowning amount [\%] } \\
\hline Scenario & Sun & Planet & Ring \\
\hline 1 & 150 & 150 & 150 \\
\hline 2 & 125 & 125 & 125 \\
\hline 3 (current design) & 100 & 100 & 100 \\
\hline 4 & 75 & 75 & 75 \\
\hline 5 & 50 & 50 & 50 \\
\hline
\end{tabular}

In order to study the simultaneous effect of crowning and surface roughness on power loss, a map of these values is generated. Figure 3 shows the total power loss with different crowning and surface roughness. Figure 4 represents percentage change in the total power loss with respect to the current base design. Referring to Figures 3 and 4, the power loss of the planetary gear sets can be reduced by as much as $5 \%$. However, considering the high efficiency of these gear sets, the absolute value of this reduction only amounts to $45 \mathrm{~W}$ per meshing cycle. This gain in efficiency should be set against the entailing manufacturing costs, indicating little incentive for implementation.

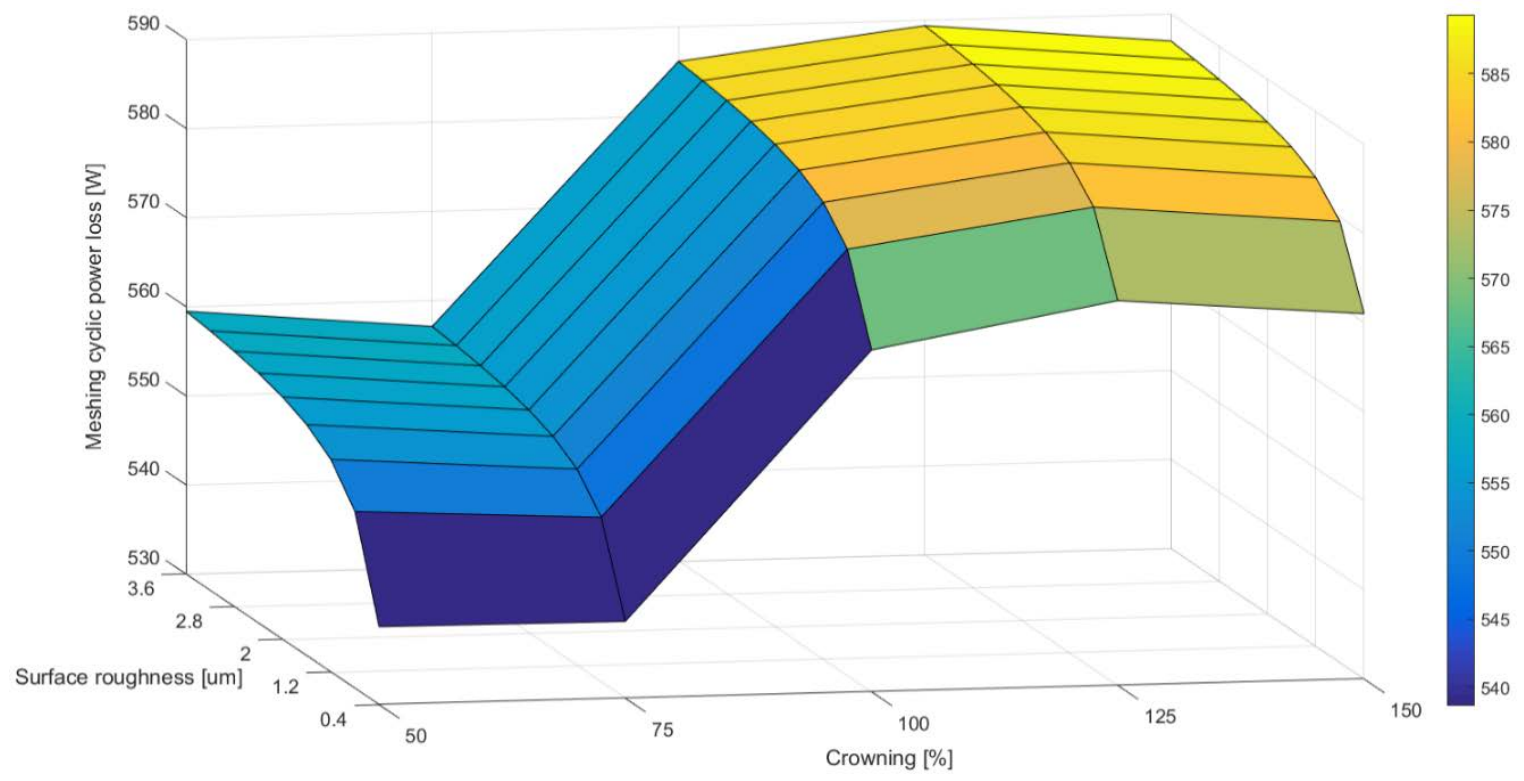

Figure 3: Meshing cyclic power loss with different surface topography and crowning 


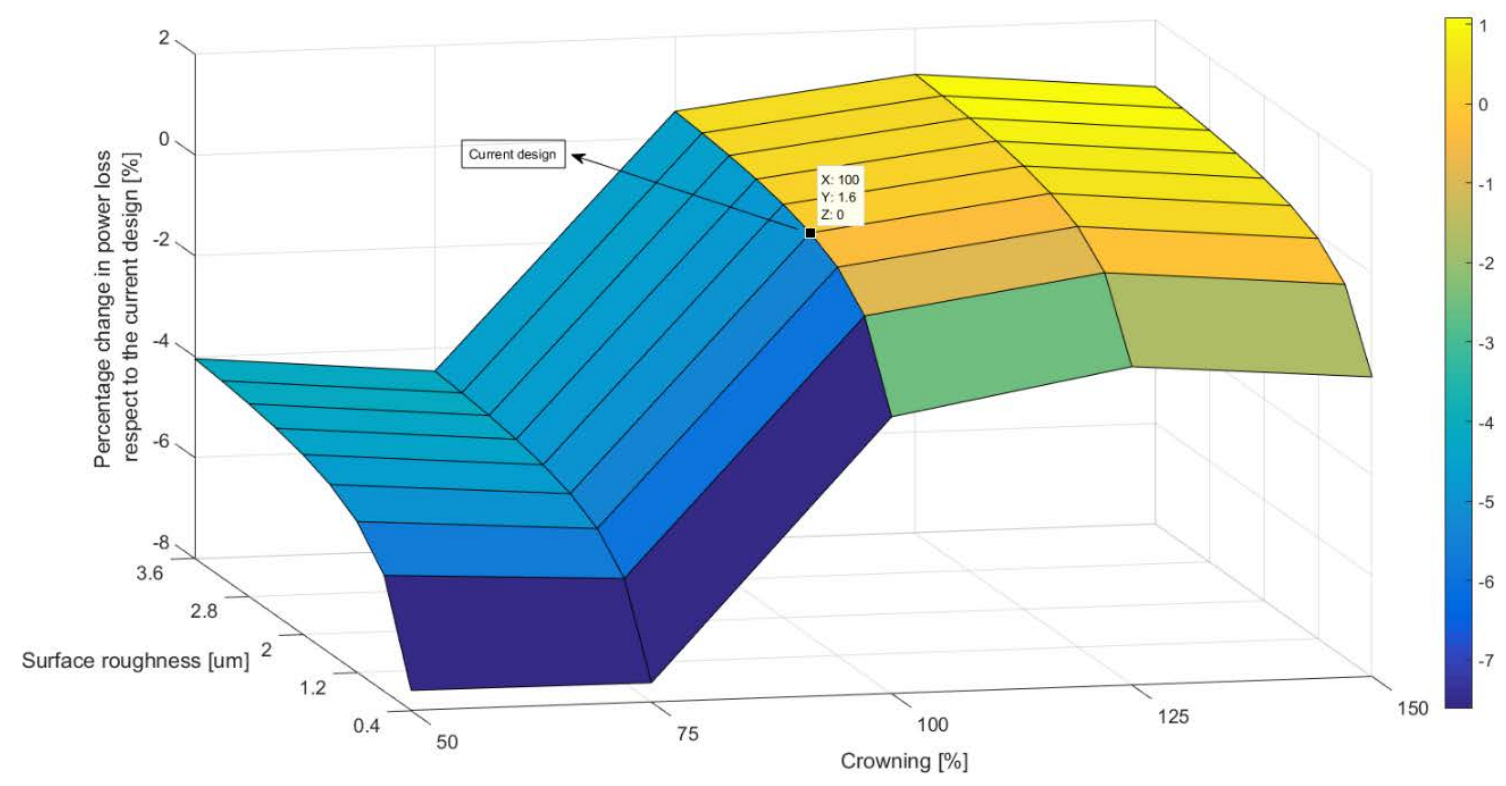

Figure 4: Percentage change in power loss with different crowning and surface roughness

Finally, Figure 5 shows the cyclic precession of contact footprint for different crowning cases for both the planet-ring and the sun-planet contacts. It can be seen that the contact is concentrated at the centre of the footprint area with increased crowning. This avoids generation of edge stress discontinuity. Therefore, in terms of contact fatigue and useful life some gain would be expected due to reduced sub-surface stressing [24]. However, the reduced cross-section can lead to increased root stresses with higher contact pressures because of reduced contact footprint dimensions, requiring further in-depth analysis. 


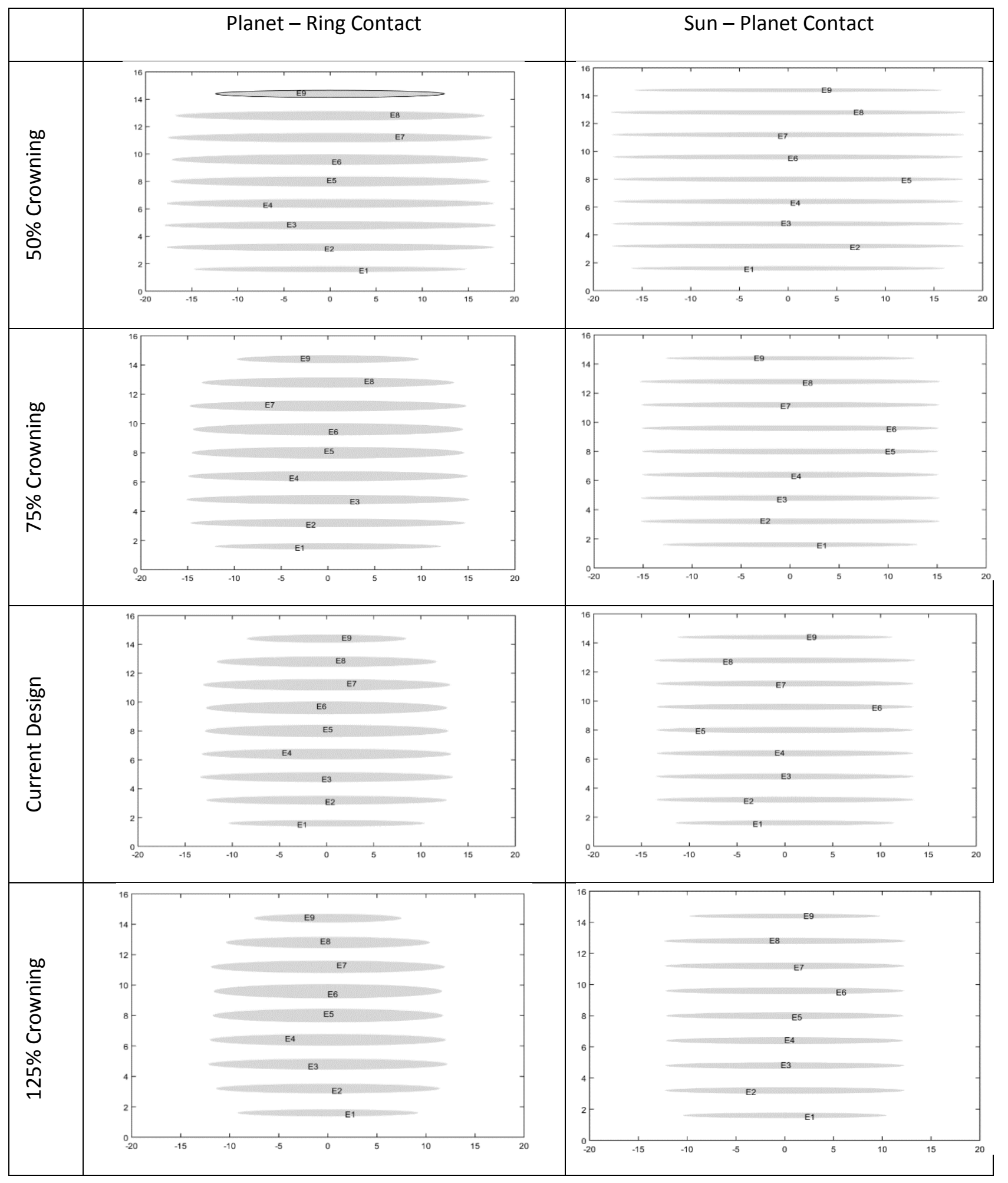




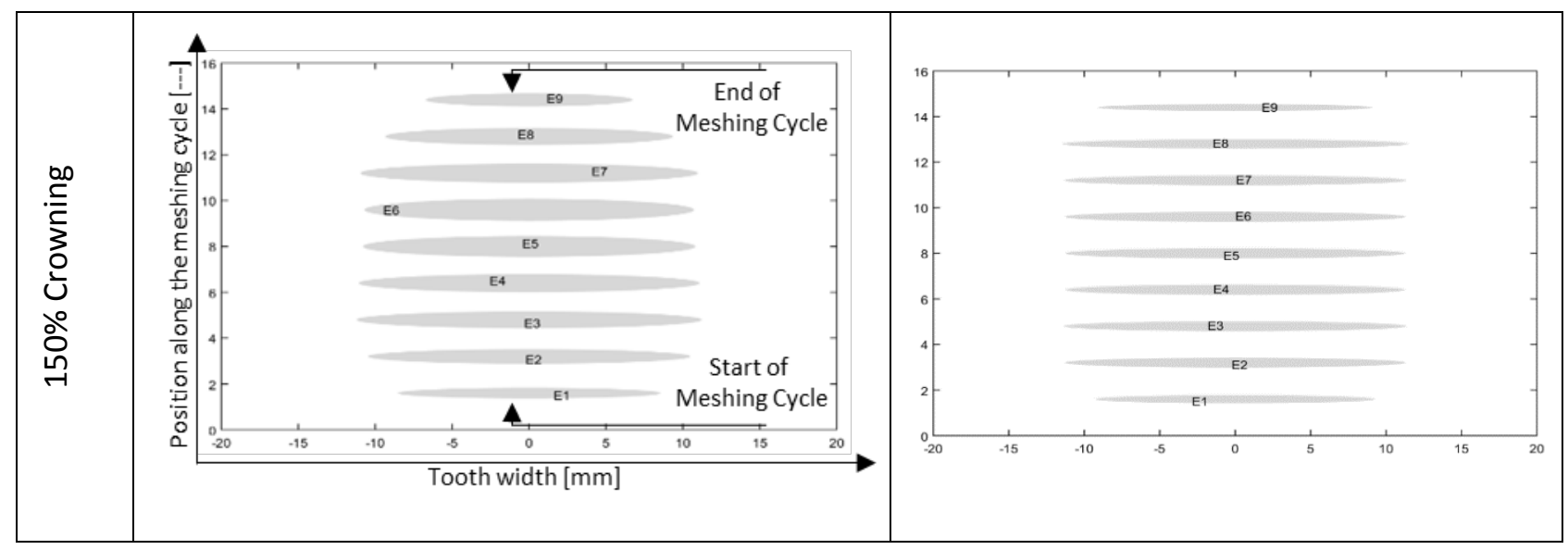

Figure 5: Contact footprints for different crowning case studies

To investigate the accuracy of optimum point, further optimisation analyses are carried out in the vicinity of the optimum point (75\%) in steps of 5\% changes. Figure 6 shows the percentage change in the total power loss in each case with respect to the current base crowning design

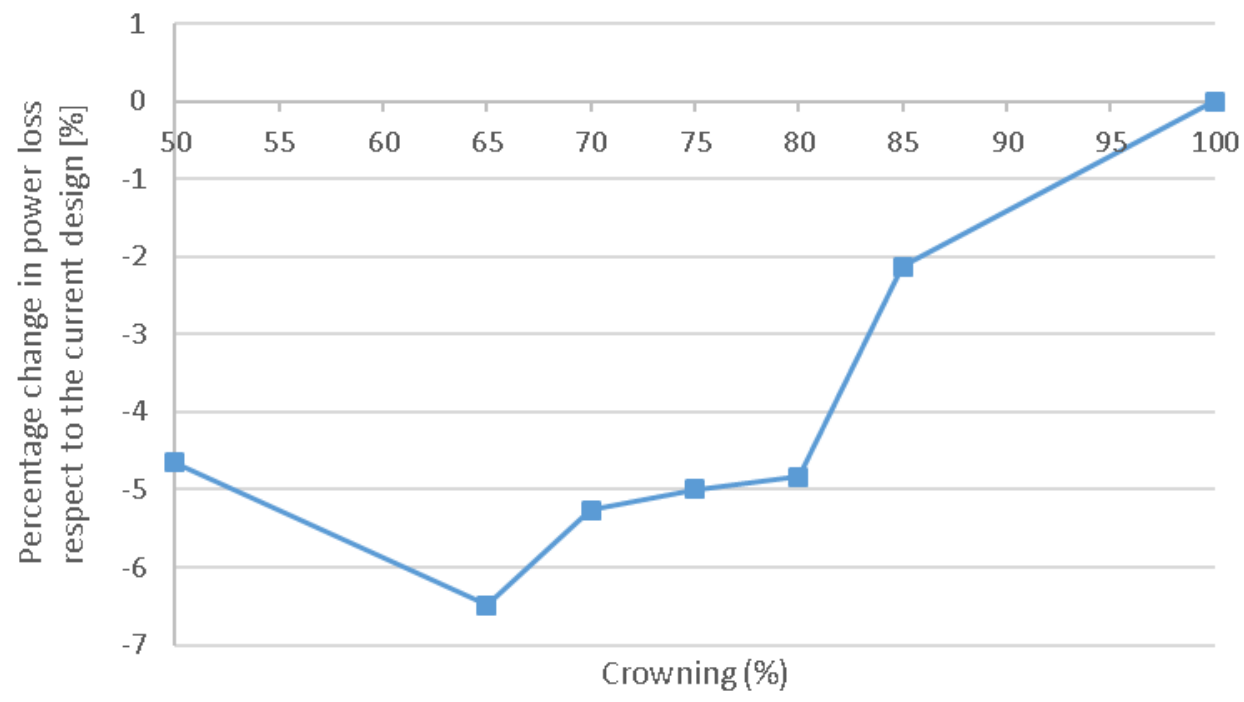

Figure 6: Percentage change in power loss with respect to the current design with 50\% - 100\% crowning change (with surface roughness of $1.6 \mu \mathrm{m}$ )

With these further steps in the optimisation process the optimum point has moved to $65 \%$ crowning with respect to the current case. However, a mere reduction of $8 \mathrm{~W}$ in power loss is only accrued (i.e. 1\% reduction). Therefore, it can be concluded that the crowning amount falls in the range $50 \%-80 \%$ would be beneficial. 


\section{2- Effects of tip relief}

At the beginning and the end of a meshing cycle with no tip relief, an impact and sharp rise in the generated contact pressure would ensue. In order to attenuate this effect, the involute profile in the tip region is relieved. An optimum length of tip relief region would enable smoother load variation from a pair of teeth to the next. The extent of tip relief in length and amount should be determined (see Figure 2(b)).

\subsection{1- Effects of tip relief amount}

In order to study the effect of tip relief amount on the gear pair power loss, the amount of tip relief is changed from $25 \%$ to $150 \%$ of the current base design. Amounts of tip reliefs for different cases are listed in Table 2.

Table 2: Amount of tip relief for different scenarios

\begin{tabular}{|c|c|c|c|}
\hline & \multicolumn{3}{|c|}{ Tip relief amount [\%] } \\
\hline Scenario & Sun & Planet & Ring \\
\hline 1 & 150 & 150 & 150 \\
\hline 2 & 125 & 125 & 125 \\
\hline 3 (Current-Design) & 100 & 100 & 100 \\
\hline 4 & 75 & 75 & 75 \\
\hline 5 & 50 & 50 & 50 \\
\hline 6 & 25 & 25 & 25 \\
\hline
\end{tabular}

A map of the results obtained is illustrated in Figure 7, showing the total power loss with different tip relief amount and surface roughness. Figure 8 represents the percentage change in the total power loss with respect to the current design. It shows that the overall power loss can be reduced by $12 \%$ in comparison with the current design. This value, in absolute term, is approximately 70W. The results reveal that the effect of tip relief on the frictional power loss is much more pronounced than in the case of crowning. 


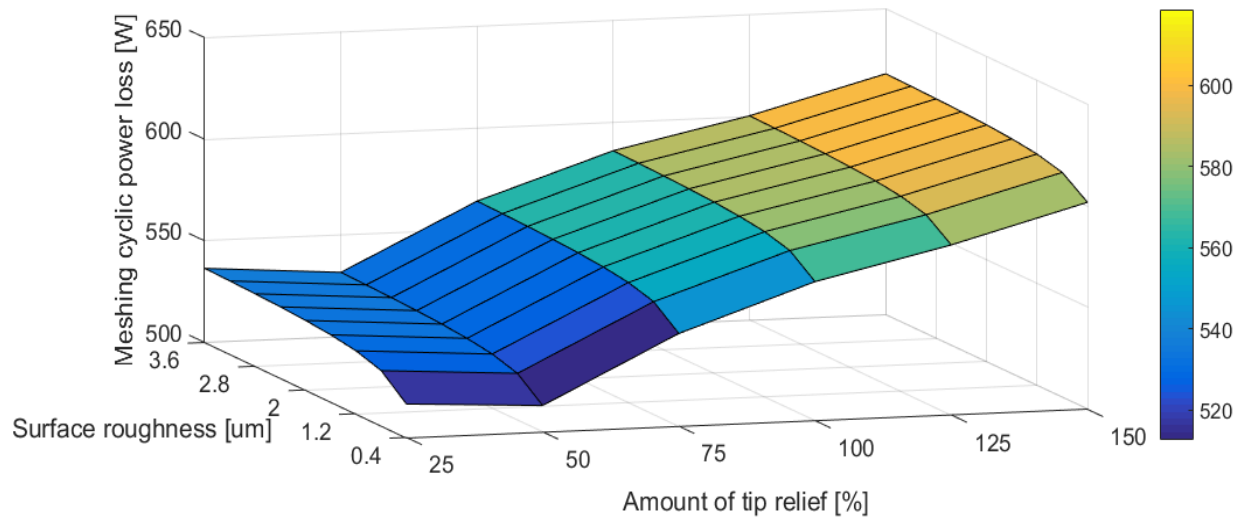

Figure 7: Meshing cyclic power loss with different surface topography and tip relief amount

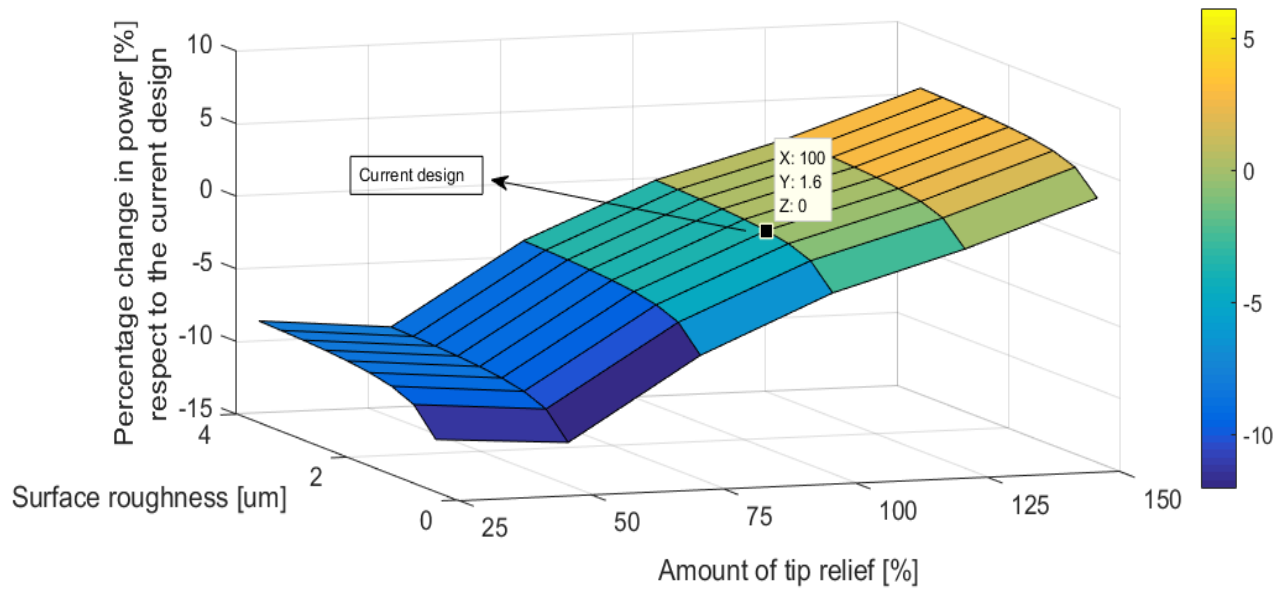

Figure 8: Percentage change in power loss with different surface roughness and tip relief amount

To further investigate the accuracy of the obtained optimum point, the optimisation steps are further reduced in its vicinity (i.e. 50\% relief in steps of 5\%). Figure 9 shows the percentage change in the total power loss with respect to the current base design for the various relieved amounts between $25 \%-75 \%$ of the existing design. 


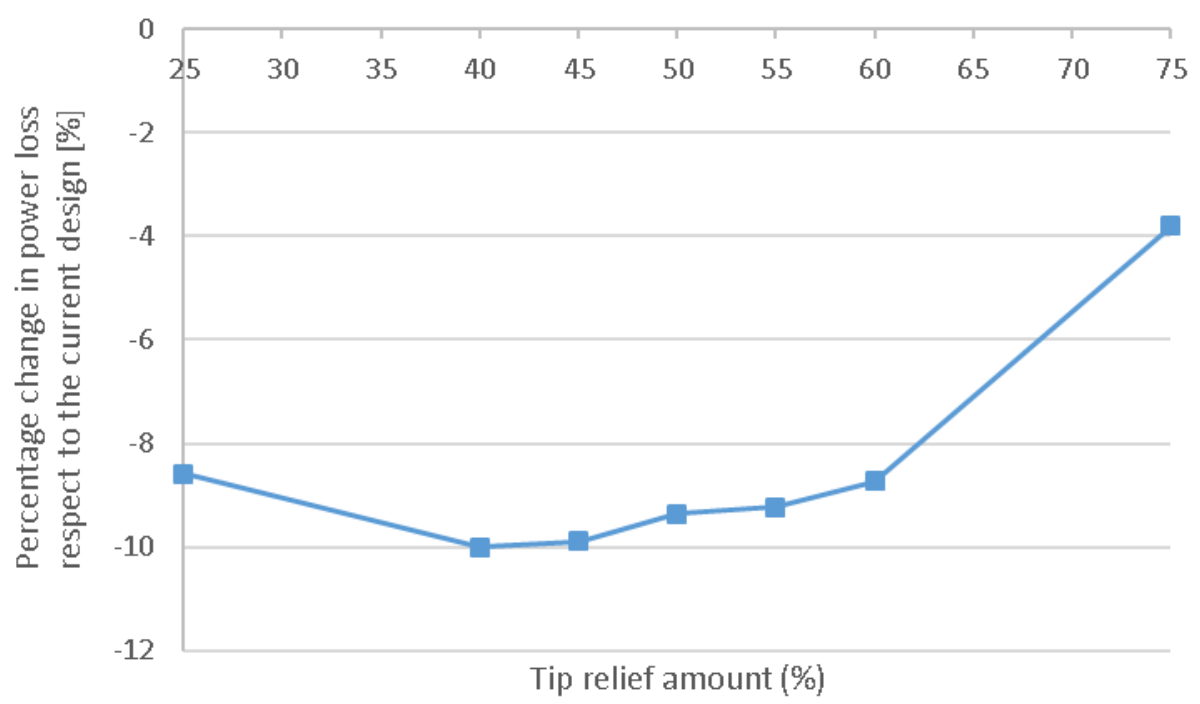

Figure 9: Percentage change in power loss with respect to the current design for $25 \%$ - $75 \%$ tip relief amount (with surface roughness of $1.6 \mu \mathrm{m}$ )

Figure shows that the 50\% tip relief amount is indeed the optimum case.

\subsection{2- Effect of tip relief length}

In order to study the effect of change by the extent (length) of tip relief (specified as $h$ in Figure 2(b)) on power loss, this is reduced from the current design (base value) by 25\%. Table 3 shows the changes in the relief length for different cases.

Table 3: Length of tip relief for different scenarios

\begin{tabular}{|c|c|c|c|}
\hline \multirow{2}{*}{ Scenario } & \multicolumn{3}{|c|}{ Length of tip relief [\%] } \\
\cline { 2 - 4 } & Sun & Planet & Ring \\
\hline 1(Current-Design) & 100 & 100 & 100 \\
\hline 2 & 75 & 75 & 75 \\
\hline 3 & 50 & 50 & 50 \\
\hline 4 & 25 & 25 & 25 \\
\hline
\end{tabular}

Figure 10 show the total power loss with different length of tip relief and surface roughness. Figure 11 shows the percentage change in the total power loss with respect to the current design. It shows that the power loss can be decreased by as much as $10 \%$, representing a $50 \mathrm{~W}$ reduction per meshing cycle. 


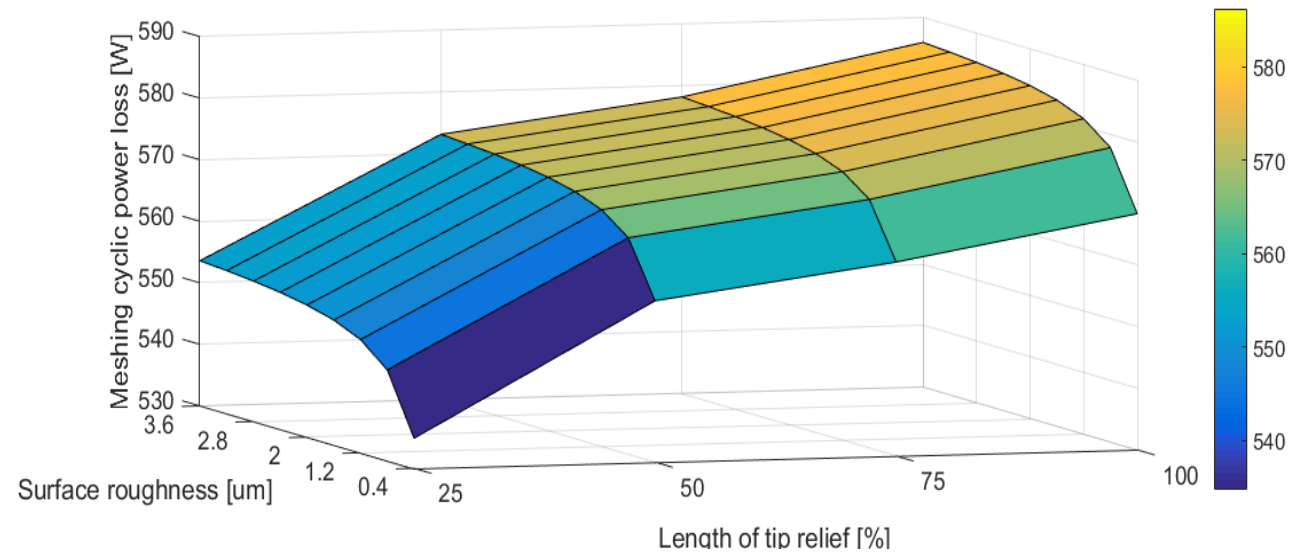

Figure 10: Cyclic meshing power loss with different surface topography and tip relief length

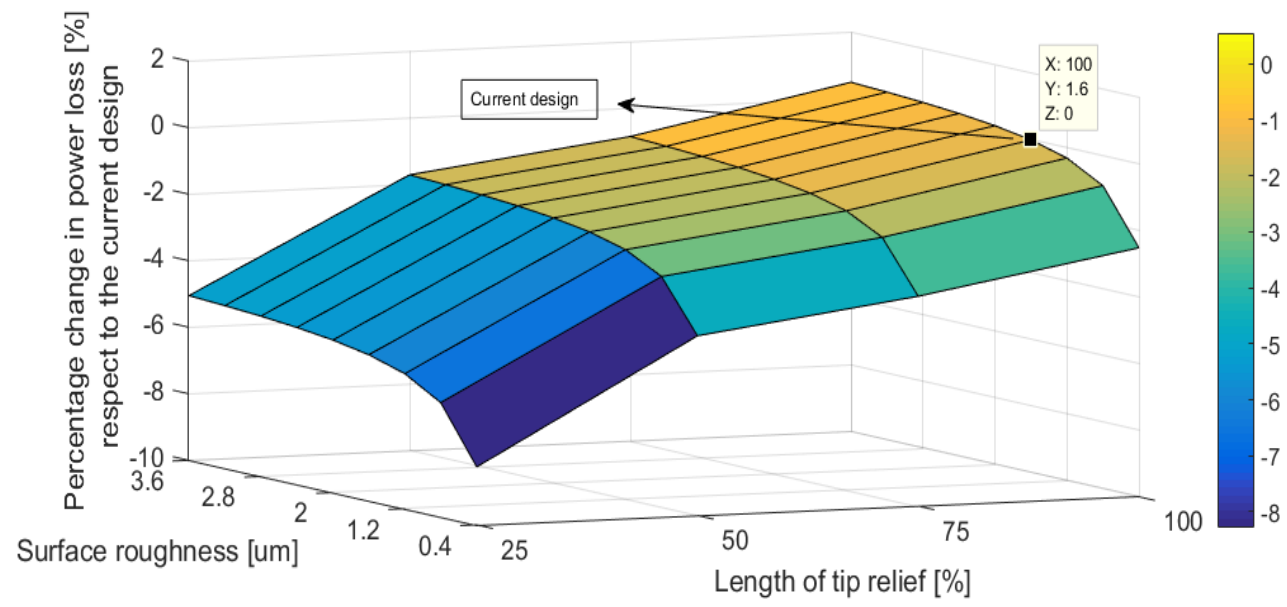

Figure 11: Percentage change in power loss with different surface roughness and tip relief length

Applying a 25\% tip relief length yields the highest power loss reduction. However, the smaller the tip relief length, the higher the chance of scuffing due to the depletion of the lubricant film This is caused by a reversal in surface velocity (Figure 12) with a higher change in curvature near the tip. With the reversal in surface velocity the inlet to the contact changes direction with momentary cessation of lubricant entrainment at zero contact velocity. This condition is noted in reciprocating contacts such as that of piston-cylinder system [28], and for high pressure elastohydrodynamic conditions at either sides of the cam-nose to a flat tappet contact [29]. Both these cases are studied in more detail in literature and show adverse lubrication conditions. 


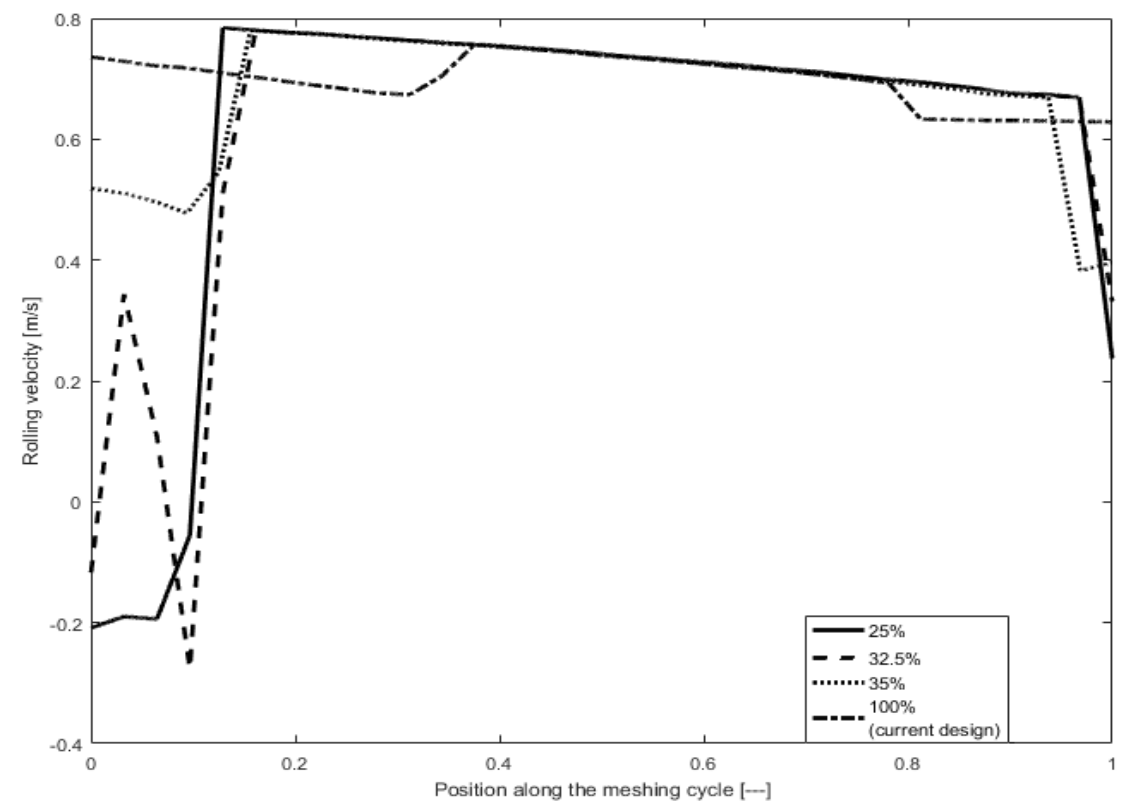

Figure 12: Sun-Planet contact - Rolling velocity along the meshing cycle for different tip relief length cases

Results of TCA analyses for 25\%, 30\%, 32.5\%, 35\% and 37.5\% tip relieves show that contact velocity reversal occurs for 25\%, 30\% and 32.5\% in Sun-Planet contact. Therefore, the length of the tip relief for the Sun-Planet contact should exceed 35\% due to high durability risk. A tip relief of 35\% is also the optimum point in terms of the efficiency as shown in Figure 13.

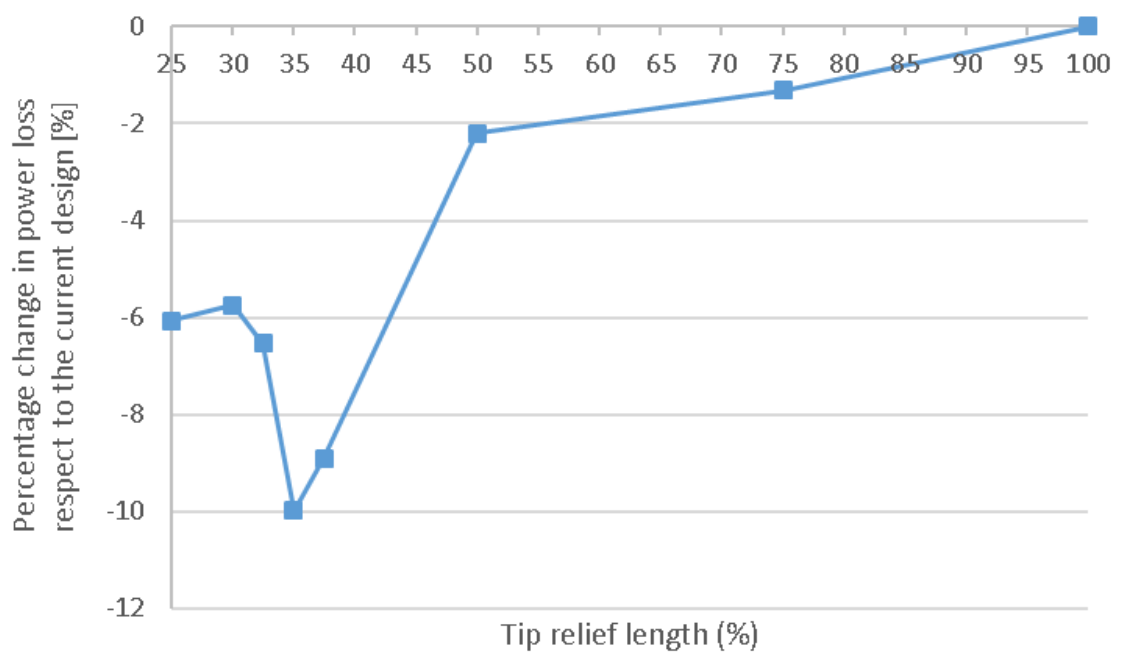

Figure 13: Percentage change in power loss with respect to the current design for the $25 \%$ - $100 \%$ (current design) tip relief length cases surface roughness of $1.6 \mu \mathrm{m}$ ) 


\section{5- Conclusions}

The study investigates the effect of tooth crowning and tip relief (length and amount) modifications on the power loss of planetary wheel hub gears of off-highway vehicles.

The following conclusions are made:

I. Better surface finish with both crowning and tip relief modifications reduces the gear contact power loss. This is because of a reduction in boundary friction.

II. Reduction of crowning by 35\% with respect to current design minimises the power loss. This is because of reduced contact pressures and an increased lubricant film thickness, thus reducing the extent of asperity interactions.

III. In terms of tip relief modification, decreasing both the amount of tip relief (to $50 \%$ of the current base design value) and length (by 65\%) leads to reduced power loss. This is mostly due to an increase in the duration of single contact time along the meshing cycle with the highest applied load. However, this effect can have adverse effect on the root stresses and potential adverse component reliability. Furthermore, applying tip relief decreases radii of curvature and rolling velocity within double contact region. These are the reasons for a decreased lubricant film thickness and a correspondingly increased friction.

IV. Finally, the "optimum" scenario corresponds to the case of 65\% crowning, 50\% tip relief amount and 35\% tip relief length with $0.4 \mu \mathrm{m}$ surface roughness average with respect to the current base design, yielding a total power loss of $499 \mathrm{~W}$ for both the planetary wheel hub gearing of the axle. The total power loss for the current design is $583 \mathrm{~W}$.

\section{Acknowledgements}

The authors wish to express their gratitude to Innovate UK under the off-highway research initiative and JCB for the financial support extended to this research and development project. 


\section{References}

[1]- Talbot, D.C., Kahraman, A. and Singh, A., “An experimental investigation of the efficiency of planetary gear sets”, Trans. ASME, J. Mechanical Design, 134(2), 2012: 021.

[2]- Dareing, D.W. and Johnson, K.L., "Fluid film damping of rolling contact vibrations”, J. Mechanical Engineering Science, 1975, 17(4): 214-218.

[3]- Mehdigoli, H., Rahnejat, H. and Gohar, R., "Vibration response of wavy surfaced disc in elastohydrodynamic rolling contact”, Wear, 1990, 139(1): 1-5.

[4]- Li, S. and Kahraman, A., "Prediction of spur gear mechanical power losses using a transient elastohydrodynamic lubrication model”, Tribology Transactions, 2010, 53(4):554-563.

[5]- De la Cruz, M., Chong, W.W.F., Teodorescu, M., Theodossiades, S. and Rahnejat, H., “Transient mixed thermo-elastohydrodynamic lubrication in multi-speed transmissions", Tribology International, 2012, 49: 17-29.

[6]- Mohammadpour, M., Theodossiades, S., Rahnejat, H. and Kelly, P., "Transmission efficiency and noise, vibration and harshness refinement of differential hypoid gear pairs”, Proc. IMechE, Part K: J. Multi-body Dynamics. 2014, 228(1): 19-33.

[7]- Mohammadpour, M., Theodossiades, S., Rahnejat, H. and Saunders, T., "Non-Newtonian mixed elastohydrodynamics of differential hypoid gears at high loads”, Meccanica, 49(5):11151138.

[8]- Evans, C.R. and Johnson, K.L., "Regimes of traction in elastohydrodynamic lubrication," Proc. IMechE, Part C: J. Mechanical Engineering Science, 1986, 200(5): 313-324.

[9]- Chittenden, R. J., Dowson, D., Dunn, J. F. and Taylor, C. M., “A theoretical analysis of the isothermal elastohydrodynamic lubrication of concentrated contacts. II. General Case, with lubricant entrainment along either principal axis of the Hertzian contact ellipse or at some intermediate angle”, Proc. Roy. Soc., Ser. A, 1985, 397: 271-294.

[10]- Gohar, R. and Rahnejat, H., "Fundamentals of Tribology”, Imperial College Press, London, 2008. 
[11]- Fatourehchi, E., Elisaus, V., Mohammadpour, M., Theodossiades, S. and Rahnejat, H., "Efficiency and durability predictions of high performance racing transmissions", SAE International Journal of Passenger Cars-Mechanical Systems, 2016, 9(2016-01-1852).

[12]- Marques, P.M., Camacho, R., Martins, R.C. and Seabra, J.H., "Efficiency of a planetary multiplier gearbox: Influence of operating conditions and gear oil formulation”, Tribology International, 2015, 92: 272-280.

[13]- Inalpolat, M. and Kahraman, A., "Dynamic modelling of planetary gears of automatic transmissions”, Proc. IMechE, Part K: J. Multi-body Dynamics. 2008, 222(3):229-242.

[14]- Mohammadpour, M., Theodossiades, S. and Rahnejat, H., "Dynamics and efficiency of planetary gear sets for hybrid powertrains”, Proc. IMechE, Part C: J. Mechanical Engineering Science, 2016, 230(7-8): 1359-1368.

[15]- Vijayakar, S., “CALYX manual”, Advanced Numerical Solutions Inc, Columbus, Ohio, USA, 2000.

[16]- Xu, H. and Kahraman, A., "Prediction of friction-related power losses of hypoid gear pairs”, Proc. IMechE, Part K: J. Multi-body Dynamics, 2007, 221(3):387-400.

[17]- Karagiannis, I., Theodossiades, S. and Rahnejat, H., “On the dynamics of lubricated hypoid gears”, Mechanism and Machine Theory. 2012, 8: 94-120.

[18]- Mohammadpour, M., Theodossiades, S. and Rahnejat, H., “Transient mixed non-Newtonian thermo-elastohydrodynamics of vehicle differential hypoid gears with starved partial counterflow inlet boundary”, Proc. IMechE, Part J: J. Engineering Tribology, 2014, 228(10): 1159-1173.

[19]- Greenwood, J.A. and Tripp J.H., "The contact of two nominally flat rough surfaces”, Proc. IMechE, Part C: J. Mechanical Engineering Science, 1970, 185: 625-633.

[20]- Teodorescu, M., Balakrishnan, S. and Rahnejat, H., "Integrated tribological analysis within a multi-physics approach to system dynamics”, Tribology and Interface Engineering Series, 2005, 48: 725-737. 
[21]- Leighton, M., Morris, N., Rahmani, R. and Rahnejat, H., “Surface specific asperity model for prediction of friction in boundary and mixed regimes of lubrication”, Meccanica, 52(1-2): 2133.

[22]- Johns, P.M. and Gohar, R., "Roller bearings under radial and eccentric loads”, Tribology International, 1981, 14(3):131-136.

[23]- Kushwaha, M., Rahnejat, H. and Gohar, R., "Aligned and misaligned contacts of rollers to races in elastohydrodynamic finite line conjunctions”, Proc. IMechE, Part C: J. Mechanical Engineering Science, 2002, 216(11):1051-1070.

[24]- Johns-Rahnejat, P.M. and Gohar, R., "Point contact elastohydrodynamic pressure distribution and sub-surface stress field”, In Tri-Annual Conference on Multi-Body Dynamics: Monitoring and Simulation Techniques, 1997.

[25]- Johns, P.M., “The design of cylindrical rollers for use in shaft and bearing systems”, Diss. MSc Thesis, Imperial College of Science and Technology, London, 1978.

[26]- Seol, I. H. and Kim, D. H., “The Kinematics and Dynamic Analysis of Crowned Spur Gear Drive”, Comput. Methods Appl. Mech. Eng., 1998, 167:109-118.

[27]- Simon, V., “'Optimal Tooth Modifications for Spur and Helical Gears”, Trans. ASME, J. Mech. Trans. Auto. Design, 1989, 111: 611-615.

[28]- Dowson, D., Ruddy, B.L. and Economou, P.N., "The elastohydrodynamic lubrication of piston rings”, Proc. Royal Society, A: Mathematical, Physical and Engineering Sciences, 1983, 386(1791): 409-430

[29]- Balakrishnan, S. and Rahnejat, H., "Isothermal transient analysis of piston skirt-to-cylinder wall contacts under combined axial, lateral and tilting motion”, J. Physics, D: Applied Physics, 2005, 38(5):787.

[30]- Kushwaha, M. and Rahnejat, H., “Transient elastohydrodynamic lubrication of finite line conjunction of cam to follower concentrated contact”, J. Physics, D: Applied Physics, 2002, 35(21):2872.

\section{Nomenclature:}

A: $\quad$ Apparent contact area 

$A_{a}: \quad$ Asperity contact area
$c^{\prime}: \quad$ Specific heat capacity of the solid surfaces
$E_{r}: \quad$ Reduced elastic modulus of the contact
$E^{\prime}: \quad$ Reduced elastic modulus of the contact, $\left(2 \mathrm{E}_{\mathrm{r}}\right) / \pi$

EHL: Elastohydrodynamic Lubrication

$f_{v}: \quad$ Viscous friction

$f_{b}: \quad$ Boundary friction

$h_{c 0}^{*}$ : Dimensionless central lubricant film thickness

$h_{c 0}$ : Central lubricant film thickness

$K$ : $\quad$ Lubricant's thermal conductivity

$K^{\prime}$ : $\quad$ Thermal conductivity of the solids

$\bar{p}: \quad$ Average (Laplace) contact pressure

$P_{m}: \quad$ Mean pressure

$R: \quad$ Effective radii of curvature

$R_{x}: \quad$ Radii of curvature along the direction of sliding

$R_{y}: \quad$ Radii of curvature along the direction of side leakage

TCA: Tooth Contact Analysis

$U_{r}: \quad$ Rolling velocity

$U_{s}: \quad$ Sliding velocity

$U: \quad$ Speed of entraining motion

$W_{a}: \quad$ Asperity load share

$\alpha: \quad$ Pressure viscosity coefficient

$\beta: \quad$ Average asperity tip radius

$\varepsilon: \quad$ Slope of the lubricant limiting shear stress-pressure dependence

$\eta_{0}: \quad$ Lubricant dynamic viscosity at atmospheric pressure 
$\lambda: \quad$ Stribeck's oil film parameter

$\mu: \quad$ Coefficient of friction

$\xi: \quad$ Asperity density per unit area

$\rho^{\prime}: \quad$ Density of solids

$\sigma: \quad$ Composite RMS surface roughness

$\tau_{0}: \quad$ Ambient value of lubricant limiting shear stress

$\tau_{L}: \quad$ Limiting shear stress

Table 4: Lubricant properties

\begin{tabular}{|l|l|}
\hline Pressure viscosity coefficient $\left(\mathrm{Pa}^{-1}\right)$ & $2.38 \times 10^{-8}$ \\
\hline Lubricant Atmospheric dynamic viscosity at $100^{\circ} \mathrm{C}(\mathrm{Pa} . \mathrm{s})$ & 0.0144 \\
\hline Ambient value of lubricant limiting shear stress $(\mathrm{MPa})$ & 2 \\
\hline Thermal conductivity of fluid $(\mathrm{W} / \mathrm{mK})$ & 0.140 \\
\hline Pressure-induced shear coefficient $(\varepsilon)$ & 0.047 \\
\hline
\end{tabular}

